Rabaska

Revue d'ethnologie de l'Amérique française

\title{
Chaire de recherche du Canada sur l'identité métisse (CRCIM)
}

\section{Denis Gagnon}

Volume 8, 2010

URI : https://id.erudit.org/iderudit/045308ar

DOI : https://doi.org/10.7202/045308ar

Aller au sommaire du numéro

Éditeur(s)

Société québécoise d'ethnologie

ISSN

1703-7433 (imprimé)

1916-7350 (numérique)

Découvrir la revue

Citer ce document

Gagnon, D. (2010). Chaire de recherche du Canada sur l'identité métisse (CRCIM). Rabaska, 8, 322-324. https://doi.org/10.7202/045308ar d'utilisation que vous pouvez consulter en ligne.

https://apropos.erudit.org/fr/usagers/politique-dutilisation/ 


\section{OuEst}

\section{Chaire de recherche du Canada sur l'identité métisse (CRCIM)}

Collège universitaire de Saint-Boniface

200, avenue de la Cathédrale

Saint-Boniface (Manitoba)

$\mathrm{R} 2 \mathrm{H} 0 \mathrm{H} 7$

Téléphone : (204) 237-1818, poste 454

Courriel : degagnon@ustboniface.mb.ca

\section{Faits saillants}

Les événements les plus importants de l'année 2009-2010 ont été le renouvellement de la Chaire pour un second mandat de cinq ans et la tenue du troisième atelier international sur les identités et cultures métisses. Les deux premiers ateliers ont eu lieu en 2008 et 2009 au Centre de recherches d'histoire nord-américaine à l'Université Panthéon Sorbonne (Paris I) dirigé par Annick Foucrier. Subventionné par le Crsh dans le cadre du Programme d'aide aux colloques et ateliers, le troisième atelier, intitulé L'Identité métisse en question: stratégies identitaires et dynamismes culturels a été organisé en collaboration avec Annik Foucrier et a eu lieu au Collège universitaire de Saint-Boniface du 17 au 19 mai. Cet atelier a réuni treize professeurs, chercheurs et doctorants du Canada, de la France et de la Suisse. L'ouvrage collectif issu de l'atelier sera publié au Presses de l'Université Laval en avril 2011. J'ai également organisé une table ronde intitulée Les Métis francophones du Canada et l'authenticité culturelle : un premier regard anthropologique. Cette table ronde, qui réunissait mes étudiants au doctorat, Joanna Seraphim (ÉHÉss), Emmanuel Michaux (U. Laval) et Fabien Tremblay (U. de Montréal) et le chercheur Yves Labrèche dans le cadre du colloque de la Société canadienne d'anthropologie, a eu lieu le $1^{\text {er }}$ juin au congrès de la Fédération canadienne des sciences humaines à l'Université Concordia. Ces deux événements ont permis d'explorer les identités et cultures métisses au Canada et en Europe dans une perspective comparative.

\section{Collaborations}

La collaboration se poursuit avec Léonard Rivard pour le volet sauvegarde et mise en valeur du patrimoine culturel et linguistique des Métis francophones dans le cadre de la subvention de l'Aruc sur les identités francophones de l'Ouest au Collège universitaire de Saint-Boniface (CUSB). Le projet de publication de l'ouvrage collectif issu du troisième atelier sur les identités et cultures métisses en codirection avec Annick Foucrier (Panthéon Sorbonne - Paris I) demande une étroite collaboration avec les auteurs. Je collabore 
également avec Robert Papen (UQÀM) dans le cadre des travaux de la chaire et de l'ARUC. Je suis membre régulier du Centre interuniversitaire d'études et de recherches autochtones (CIÉRA) de l'Université Laval.

En octobre, j'ai reçu une subvention de la Conférence des évêques catholiques du Canada (CÉCC) et du Conseil autochtone catholique canadien (CACC) pour la rédaction d'un ouvrage intitulé Sainte Anne et le catholicisme autochtone, dévotions et pèlerinages. Juliette Champagne et Annick Chiron ont participé à la cueillette des données. La publication de ce projet sur le métissage religieux est prévue pour juillet 2011 .

J'ai été appelé en janvier 2010 à participer à la consultation bilatérale pour le futur Musée canadien des droits de la personne. Une interview a également été filmée dans le cadre de la collecte de contenu et de témoignages où j'ai présenté une mise en garde contre les tendances hégémoniques sur l'identité des Métis de l'Ouest canadien qui se considèrent les seuls Métis au Canada.

\section{Recherche}

Le titulaire et l'équipe de la Chaire ont été très sollicités par les organisations métisses et le gouvernement du Canada et du Québec. Comme les études métisses au Canada sont fortement politisées et judiciarisées, nous avons été invités d'une part par une communauté métisse du Québec pour les défendre en cour et, d'autre part, par le ministère des Affaires indiennes et du Nord du Canada pour réaliser des contre-expertises des rapports soumis par les communautés métisses. Nous avons jugé qu'il était plus important, c'est une question de liberté universitaire, de poursuivre les enquêtes ethnographiques et nos recherches sur l'identité plutôt que d'agir comme témoin expert, protégeant ainsi le titulaire et les membres de l'équipe de recherche d'une implication au niveau juridique. La problématique serait totalement différente si nous étions invités à participer au niveau de l'élaboration de politiques, mais le Canada et les provinces ont choisi la voie de la judiciarisation plutôt que celle de la législation.

Les étudiants au doctorat ont poursuivi leurs terrains dans les Maritimes, au Québec, au Manitoba et en Saskatchewan. Un doctorant a effectué des terrains auprès de la communauté métisse Magoua de Yamachiche et de la communauté de Maniwaki. Le rapport de recherche sur les Métis du Domaine du Roi et de la Seigneurie de Mingan et sur la communauté métisse de la Gaspésie a été remis à ces communautés. Cet étudiant travaille également sur la constitution d'une carte du Canada présentant la situation de la francophonie chez les Métis lors du recensement de la population en 2006.

Joanna Seraphim, doctorante sous ma codirection à l'ÉHÉss a rédigé un article sur les Métis de la Colombie-Britannique qui sera publié dans la revue 
Recherches amérindiennes au Québec. Denis Jean, étudiant de $2^{\mathrm{e}}$ cycle en histoire de l'Université de Moncton, a travaillé sur la présence métisse sur le territoire de la Gaspésie en analysant les modèles de peuplement des réfugiés métis mi'gmaq (micmacs) de 1758 et de leurs descendants en relation avec les autres groupes en présence.

J'ai également engagé deux professionnelles de recherche : Annik Chiron, qui a effectué l'analyse de vingt-neuf entrevues réalisées entre 2005 et 2008 et qui travaille présentement sur les Métis et les écoles résidentielles; et Hélène Giguère qui vit en Espagne et qui travaille sur une bibliographie annotée des ouvrages en études métisses. Enfin, Yves Labrèche, ancien chercheur postdoctoral pour la Chaire, a réalisé l'inventaire et l'archivage de tous les dossiers constitués dans le cadre des travaux de la chaire depuis 2004 selon les normes du CRSH.

Denis GaGnon

Centre canadien de recherche sur les francophonies en milieu minoritaire

Institut français

Université de Régina

3737 Wascana Parkway

Régina (Saskatchewan) S4S 0A2
Téléphone : (306) 337-3273

Télécopieur : (306) 585-5183

Courriel : sophie.bouffard@uregina.ca

Le CRFM de l'Institut français dirige, de façon multidisciplinaire et interinstitutionnelle, un programme de recherche qui porte en priorité sur l'expérience de la communauté fransaskoise, tout en s'ouvrant à celles des autres francophonies canadiennes et internationales qui cherchent à s'affirmer en milieu minoritaire. Le CRFM favorise également des recherches qui permettent de comparer cette expérience francophone à celle d'autres groupes ethnoculturels en situation minoritaire.

\section{Colloque sur la cause Caron et le statut du français dans l'Ouest canadien}

Le colloque bilingue intitulé « Le statut du français dans l'Ouest canadien : la cause Caron » a eu lieu les 19 et 20 février à l'Université de Régina. Cet événement, organisé par l'Association des juristes d'expression française de la Saskatchewan et l'Institut français, a été présenté en collaboration avec l'Assemblée communautaire fransaskoise, l'Association canadiennefrançaise de l'Alberta et la Fédération des juristes d'expression française de common law. 